\title{
Breastfeeding and drugs. A common conflict
}

When mothers are required to undergo a procedure or suffer from a psychiatric or infectious condition, it is common for them to face a dilemma: they either undergo the procedure or treatment, or maintain breastfeeding. This is a common conflict. There are certain circumstances in which both scenarios coincide: a woman with a condition requiring a procedure or treatment and the time in her life when she wishes to breastfeed her child.

Looking at some figures it might be possible to establish the size of this problem. Hypertensive disorders occur in $10 \%$ of pregnancies. The prevalence of pregnant women with Chagas disease attended at public hospitals in Argentina ranges between $3 \%$ and $17 \%$. Depression and/ or anxiety affect up to $30 \%$ of pregnant women. Infection, ileus and postpartum hemorrhage require diagnostic tests and an adequate treatment.

All these situations confront women, their families and health care professionals with the fear to the possible damage to the infant that drugs used in imaging studies or prescribed for treatment might produce. In the long run, we should also consider the risk a child might be exposed to when not breastfed. Given the scant information, some professionals choose to either temporarily discontinue breastfeeding or treatment, placing a heavier burden on the mother, who is already dealing with several difficulties.

There is an excellent web tool, www.elactancia.org, supported by a group of pediatricians in Spain, known as APILAM, Asociación para la Promoción e Investigación científica y cultural de la Lactancia Materna (Association for the Promotion and Cultural and Scientific Research in Breastfeeding), that provides information about the compatibility of more than 1600 products with breastfeeding.

By visiting this website, you can access the available evidence on the passage of a drug to the breast milk and adverse events on the infant, to establish the level of risk.

When there is no risk, a drug is classified as Level 0 . When evidence indicates a low risk (Level 1), a high risk (Level 2), or a very high risk (Level 3), the tool offers other treatment options which pose a lesser risk to the infant, if any.
It is worth noting that the evaluation of risk depends on the adverse effects reported in the scientific literature versus the potential risk of discontinuing breastfeeding in vulnerable populations. Good professional judgment that takes into account all variables allows to choose the most adequate option for each case.

When analyzing some specific situations, it is observed that drugs used as contrast agents in imaging studies (ioversol used in arteriograms, computed tomographies, intravenous urographies, angiographies, angiocardiographies, and gadoterate meglumine used in magnetic resonance imaging) are compatible with breastfeeding. Both drugs are classified as Level 0 of risk $\square$ because they are inert, they are readily eliminated with almost no metabolization nor iodine release, they are not excreted by milk and are not orally absorbed." 1

Such information should be available in these women's medical records. It can be printed and shared with the family, health care providers and any other services involved. Having a consistent discourse prevents the unnecessary discontinuation of breastfeeding, brings peace of mind to families, reduces the stress caused by having a disease and the inconvenience of having to modify the child's feeding mode. The recommendation to print and distribute information is based on the fact that there are many parties involved in the health care process, and those who are usually more set apart from scientific information are those who are most frequently in contact with patients (members of admission and secretary's office staff). Training all those involved in the process is a health action with a major impact on end results.

Few weeks ago, Archives of Diseases in Childhood published an interesting article on the administration of benznidazole to breastfeeding women with Chagas disease. ${ }^{2}$ This study approaches two important topics. First of all, "orphan" diseases, i.e., those that have not been "adopted" by the pharmaceutical industry because they are not an economic incentive for manufacturing and selling drugs, either due to their rarity or because they affect low-resource populations who cannot afford drugs.

In this case, investigators do not clarify who provided the drug to mothers participating 
in the study, but it is very praiseworthy that there is someone looking into how to leverage the opportunity of having a most vulnerable population reaching out into the health system.

Regarding the management of infectious diseases, breastfeeding is the most effective approach to reduce infant morbidity and mortality among vulnerable populations, such as those affected by Chagas disease. ${ }^{3}$ In this case, it is not necessary to choose between the health of the mother or the baby. Until recently, benznidazole was considered a Level 1 drug (mild or unlikely risk). In January 2014, its status was changed to a Level 0 risk after the publication of studies similar to the one referenced here.

In relation to psychotropic drugs, it is necessary to find a balance between a dose that will allow the mother to remain stable and the level of consciousness of the infant.

Most antidepressants are compatible with breastfeeding. Continuing breastfeeding is convenient not only because of the benefits for the infant, also because it is particularly helpful to the mother. A woman who manages to breastfeed has her self-esteem reinforced, maintains her emotional balance and strengthens her bond with the baby. It should be noted that depression is one of the risk factors for breastfeeding. ${ }^{4}$ Given that the first weeks after giving birth are critical for breastfeeding promotion and protection, a desirable goal would be to have staff members who are trained on counseling helping these mothers to achieve the best breastfeeding possible. A close follow-up would allow to set an adequate antidepressant dose for the mother that will not affect the infant's level of consciousness.

To sum up, very few drugs are absolutely contraindicated during breastfeeding. Long-term use of drugs can be regulated so as to promote the well-being of both mothers and infants. Information should be searched and shared with the family and treating professionals in order to standardize concepts for the benefit of all those involved.

I would like to make a final reflection regarding mothers who require treatment with drugs that are a contraindication, either temporary or permanent, to breastfeeding: cytotoxic drugs for cancer treatment, radioactive drugs and substances of abuse.

This encompasses a wide range of circumstances, from mothers who require cancer treatment to those who use a toxic substance, including nicotine. Medicine is art and science; a wise combination thereof will allow us to find the best option for each family based on the elements we have before us and to the largest extent possible. We should make our best effort to avoid making wrong decisions and also to accept the situations that we cannot change.

\section{Norma Rossato Division of Neonatology Sanatorio de la Trinidad Palermo}

http: / / dx.doi.org/10.5546/ aap.2015.eng.4

1. Ioversol. Riesgo para la lactancia. [Accessed on: October 28, 2014]. Available at: http://e-lactancia.org/ buscar?q=Ioversol.

2. García-Bournissen F, Moroni S, Marson ME, Moscatelli $G$, et al. Limited infant exposure to benznidazole through breast milk during maternal treatment for Chagas disease. Arch Dis Child 2014 Sep 10. pii: archdischild-2014-306358. [Epub ahead of print].

3. Lutter C. ¡El inicio temprano de la lactancia materna: la clave para supervivencia y desarrollo! Washington DC: Organización Panamericana de la Salud; 2010. [Accessed on: October 29, 2014]. Available at: http:/ / publicaciones. ops.org.ar/publicaciones / piezas\% 20 comunicacionales / cdLactanciaM/cd / informacion+Reciente/Eight $\% 20$ Pager $\% 20$ Spanish $\% 20$ FINAL $\% 5 B 1 \% 5 D$.pdf

4. AdedinsewoDA,FlemingAS,SteinerM,MeaneyMJ,etal.Maternal anxiety and breastfeeding: findings from the MAVAN (MaternalAdversity, Vulnerability and Neurodevelopment) Study. J Hum Lact 2014;30(1):102-9. 